\title{
The effects of a limited infusion rate of fluid in the early resuscitation of sepsis on glycocalyx shedding measured by plasma syndecan-1: a randomized controlled trial
}

\author{
Jutamas Saoraya ${ }^{1,2}$, Lipda Wongsamita ${ }^{2}$, Nattachai Srisawat ${ }^{3,4,5}$ and Khrongwong Musikatavorn ${ }^{2,6^{*}}$
}

\begin{abstract}
Background: Aggressive fluid administration is recommended in the resuscitation of septic patients. However, the delivery of a rapid fluid bolus might cause harm by inducing degradation of the endothelial glycocalyx. This research aimed to examine the effects of the limited infusion rate of fluid on glycocalyx shedding as measured by syndecan-1 in patients with sepsis-induced hypoperfusion.

Methods: A prospective, randomized, controlled, open-label trial was conducted between November 2018 and February 2020 in an urban academic emergency department. Patients with sepsis-induced hypoperfusion, defined as hypotension or hyperlactatemia, were randomized to receive either the standard rate $(30 \mathrm{ml} / \mathrm{kg} / \mathrm{h})$ or limited rate $(10 \mathrm{ml} / \mathrm{kg} / \mathrm{h})$ of fluid for the first $30 \mathrm{ml} / \mathrm{kg}$ fluid resuscitation. Subsequently, the fluid rate was adjusted according to the physician's discretion but not more than that of the designated fluid rate for the total of $6 \mathrm{~h}$. The primary outcome was differences in change of syndecan- 1 levels at $6 \mathrm{~h}$ compared to baseline between standard and limited rate groups. Secondary outcomes included adverse events, organ failure, and 90-day mortality.

Results: We included 96 patients in the intention-to-treat analysis, with 48 assigned to the standard-rate strategy and 48 to the limited-rate strategy. The median fluid volume in $6 \mathrm{~h}$ in the limited-rate group was $39 \mathrm{ml} / \mathrm{kg}$ (interquartile range [IQR] 35-52 ml/kg) vs. $53 \mathrm{ml} / \mathrm{kg}(I \mathrm{QR} 46-64 \mathrm{ml} / \mathrm{kg})$ in the standard-rate group $(p<0.001)$. Patients in the limited-rate group were less likely to received vasopressors ( $17 \% \mathrm{vs} 42 \% ; p=0.007$ ) and mechanical ventilation ( $20 \%$ vs $41 \% ; p=0.049)$ during the first $6 \mathrm{~h}$. There were no significantly different changes in syndecan-1 levels at $6 \mathrm{~h}$ between the two groups (geometric mean ratio [GMR] in the limited-rate group, 0.82; 95\% confidence interval $[\mathrm{Cl}], 0.66-1.02 ; p=0.07)$. There were no significant differences in adverse events, organ failure outcomes, or mortality between the two groups.
\end{abstract}

(Continued on next page)

\footnotetext{
* Correspondence: musikatavorn.k@gmail.com

2Department of Emergency Medicine, King Chulalongkorn Memorial Hospital,

The Thai Red Cross Society, 1873 Rama IV Road, Pathumwan, Bangkok 10330,

Thailand

${ }^{6}$ Department of Medicine, Faculty of Medicine, Chulalongkorn University,

Bangkok, Thailand

Full list of author information is available at the end of the article
}

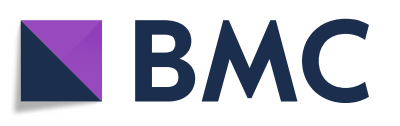

(- The Author(s). 2021 Open Access This article is licensed under a Creative Commons Attribution 4.0 International License, which permits use, sharing, adaptation, distribution and reproduction in any medium or format, as long as you give appropriate credit to the original author(s) and the source, provide a link to the Creative Commons licence, and indicate if changes were made. The images or other third party material in this article are included in the article's Creative Commons licence, unless indicated otherwise in a credit line to the material. If material is not included in the article's Creative Commons licence and your intended use is not permitted by statutory regulation or exceeds the permitted use, you will need to obtain permission directly from the copyright holder. To view a copy of this licence, visit http://creativecommons.org/licenses/by/4.0/. The Creative Commons Public Domain Dedication waiver (http://creativecommons.org/publicdomain/zero/1.0/) applies to the data made available in this article, unless otherwise stated in a credit line to the data. 
(Continued from previous page)

Conclusions: In sepsis resuscitation, the limited rate of fluid resuscitation compared to the standard rate did not significantly reduce changes in syndecan-1 at $6 \mathrm{~h}$.

Trial registration: Thai Clinical Trials Registry number: TCTR20181010001. Registered 8 October 2018, http://www. clinicaltrials.in.th/index.php?tp=regtrials\&menu=trialsearch\&smenu=fulltext\&task=search\&task2=view $1 \& i d=4064$

Keywords: Endothelial glycocalyx, Sepsis, Resuscitation, Fluid, Syndecan-1, Emergency department

\section{Background}

Early and aggressive fluid resuscitation is a mainstay treatment of sepsis-induced hypoperfusion in the emergency department (ED). Fluid resuscitation is typically administered in a bolus to promptly restore mean arterial pressure (MAP) and reverse the microcirculatory derangement. According to the Surviving Sepsis Campaign (SSC) Bundle: 2018 update, $30 \mathrm{ml} / \mathrm{kg}$ of crystalloids should be initiated in the first hour for the resuscitation of sepsis-induced hypoperfusion [1]. Typically, fluid in the resuscitation phase was given rapidly, with the rate at least $500 \mathrm{ml}$ over $15 \mathrm{~min}$ or $2000 \mathrm{ml} / \mathrm{h}$ [2]. A recent study revealed that completion of the initial $30 \mathrm{ml} / \mathrm{kg}$ fluid resuscitation within $2 \mathrm{~h}$ was associated with faster shock resolution and decreased sepsis mortality when compared with a slower infusion rate [3].

However, the benefit of rapid fluid bolus remains questionable. The hemodynamic effect of a crystalloid bolus in sepsis resuscitation is minimal and short-lived [4-6]. In a previous clinical study, a longer time to complete $30 \mathrm{ml} / \mathrm{kg}$ fluid bolus was not associated with increased mortality in patients with sepsis-induced hypoperfusion [7]. Moreover, treating septic shock with aggressive fluid therapy might be associated with harm (e.g., higher chance of intubation) and increased patient mortality [8-10].

Endothelial glycocalyx damage is one of the deleterious effects of rapid fluid bolus. The glycocalyx has an essential role in the regulation of vascular permeability. Damage to the glycocalyx leads to disruption of the endothelial surface layer, increases vascular permeability, and accelerates organ failure [11]. Previous studies have shown that fluid resuscitation causes hypervolemia and damages the endothelial glycocalyx [12-14]. A recent observational study reported an association between increased intravenous fluid volume and increased markers of glycocalyx degradation in septic patients, but these results were potentially biased by unmeasured confounders [15].

Therefore, we designed a randomized controlled trial to investigate the effects of a limited infusion rate of fluid administered during the early phase of sepsis resuscitation on levels of plasma syndecan-1, a biomarker of glycocalyx damage, compared to those of the standard fluid resuscitation rate. We hypothesized that the limited rate of fluid resuscitation would mitigate glycocalyx damages in septic patients.

\section{Methods \\ Study design and settings}

This open-label, investigator-initiated, parallel-group study with equal randomization (1:1) was conducted in an urban, academic ED. The ED has an annual census of 80,000 visits and stands in a 1500-bed, universityaffiliated tertiary care hospital. This study was approved by the Institutional Review Board, Faculty of Medicine, Chulalongkorn University (IRB No. 431/61) and was registered with the Thai Clinical Trials Registry (TCTR20181010001). This trial is reported in accordance with the Consolidated Standards of Reporting Trials (CONSORT) guidelines.

\section{Participants}

Participants were recruited between November 2018 and February 2020. All adults aged 18 years or over presenting to the ED with suspected sepsis-induced hypoperfusion, were eligible for inclusion. Patients were defined as presumed sepsis if they had suspected infection with a quick sequential organ failure assessment (qSOFA) of $\geq$ 2 according to the sepsis-3 definition [16]. Hypoperfusion was defined as a systolic blood pressure (SBP) $<90$ $\mathrm{mmHg}$, mean arterial pressure (MAP) $<65 \mathrm{mmHg}$, or blood lactate $\geq 4 \mathrm{mmol} / \mathrm{L}$. The lactate cut-off was revised to $\geq 2 \mathrm{mmol} / \mathrm{L}$ from April 2019 due to a slow recruitment rate after enrolling 20 participants. Participants were excluded if they met any of the following criteria: (1) received more than $500 \mathrm{ml}$ resuscitation fluid; (2) had SBP < 70 mmHg; (3) had a suspected other main cause of hypoperfusion (obstructive, cardiogenic, hypovolemic, such as gastrointestinal hemorrhage); (4) had concurrent acute heart failure or known left ventricular ejection fraction (LVEF) less than $40 \%$ or severely depressed LVEF by eyeballing point-of-care ultrasound (POCUS )[17]; (5) had end-stage renal disease (ESRD) with chronic renal replacement therapy (RRT); (6) had a suspected infection from dengue virus, malaria, Leptospira, and Rickettsia; (7) had the potential need for immediate surgery within $6 \mathrm{~h}$; (8) had a body mass index (BMI) $\geq 30 \mathrm{~kg} / \mathrm{m}^{2}$; (9) had concurrent acute traumatic brain injury; (10) had a do-not-attempt- 
resuscitation (DNAR) order status; (11) were transferred from another hospital; and (12) were pregnant.

\section{Randomization}

While eligible patients were identified, patients or their legal representatives were approached by the investigators to provide information about the trial. Written informed consent was obtained before for trial participation. A participant was randomized into either group at a 1:1 ratio using computer generated-block randomization, with blocks of varying sizes of 4,6 , and 8 prepared by an investigator without clinical involvement in the trial. Allocations were concealed in opaque, sealed envelopes and were opened after the informed consent was obtained. Participants were randomized into either the standard infusion rate group or the limited infusion rate group.

\section{Study interventions}

Lactated Ringer's solution (LRS) was used as an initial resuscitation fluid in both groups. For the first $30 \mathrm{ml} / \mathrm{kg}$ fluid bolus, the standard-rate group was set at a rate of $30 \mathrm{ml} / \mathrm{kg} / \mathrm{h}$ or a maximum rate of $2000 \mathrm{ml} / \mathrm{h}$, while the limited-rate group was assigned a rate of $10 \mathrm{ml} / \mathrm{kg} / \mathrm{h}$. MAP was monitored and recorded every $5 \mathrm{~min}$ using non-invasive blood pressure monitoring until target blood pressure was achieved (defined as MAP > 65 $\mathrm{mmHg}$ for at least three consecutive measurements). If the target blood pressure was not achieved within 15 min, norepinephrine was peripherally administered at a concentration of $4 \mathrm{mg}$ diluted in $250 \mathrm{ml}$ at a starting rate of $5 \mathrm{ml} / \mathrm{h}(=1.3 \mu \mathrm{g} / \mathrm{min})$ and was titrated to keep MAP > $65 \mathrm{mmHg}$. After completion of the designated fluid protocol, further fluid resuscitation rate and amounts were administered according to the physician's discretion with a rate that did not exceed that of the designated groups for the total duration of $6 \mathrm{~h}$. The use of POCUS to assist decision-making in resuscitation was mandated in every case and was performed by trained emergency medicine residents or attending physicians. The decision to insert a central venous catheter, arterial catheter, or to use corticosteroids depended on the clinician's judgment. All patients received the standard sepsis treatment as recommended in the SSC guideline 2016 and 2018 bundle update.

During the 6-h intervention, if participants exhibited signs of fluid overload, including crepitation of lungs, $\mathrm{SpO} 2$ decrease $>3 \%$ or respiratory rate increase $>5 / \mathrm{min}$ or encountered refractory hypotension despite optimizing vasopressors, or other specific reasons of the treating physicians, the protocol was terminated, and the reasons were recorded. The physician could adjust the treatment based on the patient's safety, such as prescribing diuretics for fluid overload or increasing the rate of fluid resuscitation in patients with persistent hypoperfusion.

\section{Data collection and follow-up}

At baseline, after the enrollment, we collected and recorded patient characteristics, vital signs, and laboratory tests, including blood lactate, N-terminal pro-b-type natriuretic peptide (NT-proBNP), and syndecan-1 levels. Qualitative LVEF estimations by POCUS were stratified according to the four-point cardiac rating scale: severely depressed, moderately depressed, normal, and increased LVEF [17]. Since we excluded the patients with severely depressed LVEF, we categorized the LVEF of the eligible patients into "normal to increased LVEF" and "moderately depressed LVEF." Lactate and syndecan-1 levels were measured again at $6 \mathrm{~h}$. We followed all patients until their hospital discharge for 90 days to determine the clinical outcomes. If patients were discharged before 90 days, we called the patients or their representatives by phone to determine mortality outcomes. Data were collected on paper case report forms by the investigators and entered into a REDCap software database hosted at the Faculty of Medicine, Chulalongkorn University [18].

\section{Outcomes}

The primary outcome was differences in change of syndecan-1 levels at $6 \mathrm{~h}$ compared to baseline between standard-rate and limited-rate groups. Secondary outcomes were proportions of patients with MAP $\geq 65$ $\mathrm{mmHg}$ at $1 \mathrm{~h}$ and $6 \mathrm{~h}, 6$-h lactate clearance, $\mathrm{PaO}_{2} / \mathrm{FiO}_{2}$ $(\mathrm{P} / \mathrm{F})$ ratio at $6 \mathrm{~h}$, fluid input and fluid balance at 24 and $72 \mathrm{~h}$, days alive and free of vasopressor support, mechanical ventilation or RRT up to 28 days, hospital lengthof-stay (LOS), and 28-day and 90-day all-cause mortality. The 6 -h lactate clearance was calculated by subtracting the lactate level at $6 \mathrm{~h}$ from the initial lactate level and divided by the initial lactate level (i.e., [(Initial lactatelactate at hour 6 )/Initial lactate] $\times 100 \%)$. Specified adverse events were monitored during the 6-h intervention period, which included cardiogenic pulmonary edema, new arrhythmia, and the incidence of norepinephrine extravasation. We also recorded protocol adherence and reasons for protocol termination. Serious adverse events were reported to the ethics committee.

\section{Biomarker assays}

Blood samples were collected at enrollment and $6 \mathrm{~h}$ later to determine plasma syndecan-1 levels. Samples were collected into ethylenediaminetetraacetic acid (EDTA) tubes and stored in a refrigerator before centrifugation followed by storage at $-80{ }^{\circ} \mathrm{C}$. Syndecan- 1 levels were measured using commercial enzyme-linked immunosorbent assay (ELISA) kits (Abcam, Cambridge, MA, USA). NT-proBNP levels were measured using electrochemiluminescence immunoassay analysis (Roche Diagnostics, Mannheim, Germany) 


\section{Sample size calculation}

According to earlier research, the standard deviation (SD) of syndecan-1 in septic patients is $109 \mathrm{ng} / \mathrm{ml}$ [19]. Therefore, a sample size of 98 patients would have a power of $90 \%$ to detect a reduction of $81 \mathrm{ng} / \mathrm{ml}$ in the limited-rate group, allowing for a dropout rate of $20 \%$, with a two-sided alpha level of 0.05 .

\section{Statistical analysis}

All analyses were performed according to the intentionto-treat principle. Continuous data are reported as the means with SD or medians with interquartile ranges (IQR), depending on the distribution after normality assessment by visual inspection. Due to highly skewed data, syndecan-1 levels were log-transformed to generate normal distributions and are reported as geometric means with $95 \%$ confidence intervals. Categorical data are reported as proportions. A Wilcoxon signed-rank test was used to analyze the change in syndecan- 1 from baseline to $6 \mathrm{~h}$. The primary outcome (the differences in change of syndecan-1 level at $6 \mathrm{~h}$ compared with that of the baseline between the two groups) was analyzed using linear regression and is reported as a geometric mean ratio (GMR). Secondary outcomes were analyzed with independent $t$ test, chi-square test, Fisher's exact test, or Wilcoxon rank sum test, depending on the types of data.
We did not impute missing data. However, the numbers of observations in the analysis are reported. Secondary analysis for the primary outcome included an adjusted analysis for baseline hemodynamics and the concurrent use of vasopressors. We also tested for interactions between the intervention and prespecified subgroups (baseline syndecan-1, NT-proBNP, lactate level, and Acute Physiology and Chronic Health Evaluation (APAC HE) II score). All analyses were performed using STATA version 16 (College Station, TX, USA). Statistical significance was defined as $p<0.05$.

\section{Results \\ Participants}

From November 2018 to February 2020, 249 patients were screened for eligibility, 146 patients met exclusion criteria, and 5 patients refused to participate in the trial. Ninety-eight patients were randomized to either the standard-rate or the limited-rate group. One patient in each group was excluded from the analysis because they met the exclusion criteria of undergoing emergency surgery. Regarding the primary outcome, syndecan- 1 results were missing in two cases of the standard-rate groups and in four cases of the limited infusion rate groups due to administrative reasons and loss to follow-up. In summary, 46 and 44 participants were analyzed for the

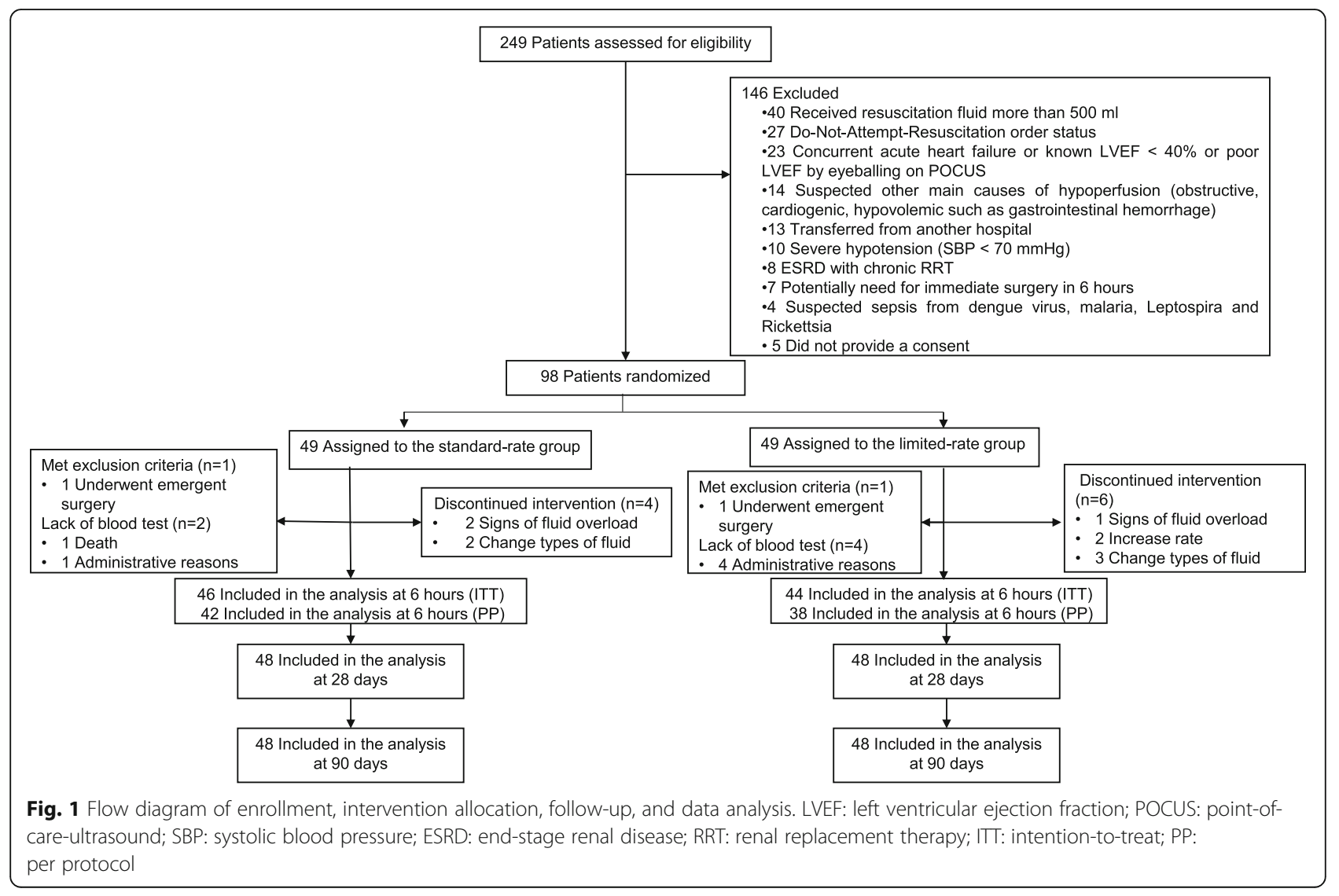


Table 1 Baseline Characteristics of the participants

\begin{tabular}{|c|c|c|}
\hline & $\begin{array}{l}\text { Standard rate } \\
(n=48)\end{array}$ & $\begin{array}{l}\text { Limited rate } \\
(n=48)\end{array}$ \\
\hline Age (years) & $72(16)$ & $70(18)$ \\
\hline Sex (female) & $18(38 \%)$ & 19(40\%) \\
\hline Body weight (kg) & $49.3(7.9)$ & $54.8(11.8)$ \\
\hline Charlson comorbidity index & $5(4,6.5)$ & $5(3,7)$ \\
\hline \multicolumn{3}{|l|}{ Comorbidities } \\
\hline Cerebrovascular disease & $30(63 \%)$ & $23(48 \%)$ \\
\hline Diabetes mellitus & $21(44 \%)$ & $20(42 \%)$ \\
\hline Malignancy & $15(31 \%)$ & $18(38 \%)$ \\
\hline Ischemic heart disease & $3(6 \%)$ & $8(17 \%)$ \\
\hline Chronic kidney disease & $1(2 \%)$ & $5(10 \%)$ \\
\hline \multicolumn{3}{|l|}{ Hypoperfusion defined by } \\
\hline Lactate $\geq 2 \mathrm{mmol} / \mathrm{L}$ & $44(90 \%)$ & $42(86 \%)$ \\
\hline Hemodynamic instability & $23(48 \%)$ & $13(27 \%)$ \\
\hline Systolic blood pressure (mmHg) & $105.9(32.8)$ & $114.3(29.8)$ \\
\hline Diastolic blood pressure (mmHg) & $58.4(20.2)$ & $66.5(17.7)$ \\
\hline Mean arterial pressure $(\mathrm{mmHg})$ & $74.6(22.7)$ & $82.3(19.9)$ \\
\hline $\begin{array}{l}\text { Body temperature (degree } \\
\text { Celsius) }\end{array}$ & $38.5(1.3)$ & $38.1(1.2)$ \\
\hline Heart rate (/min) & $117.8(28.1)$ & $119.6(24.3)$ \\
\hline Respiratory rate (/min) & $24.3(7.1)$ & $24.0(6.3)$ \\
\hline Ambient air pulse oximetry (\%) & $90.2(12.0)$ & $93.3(7.7)$ \\
\hline Currently use systemic steroid & $5(10 \%)$ & $12(25 \%)$ \\
\hline APACHE ॥ & $18.0(13.0,24.5)$ & $15.5(11.0,20.0)$ \\
\hline SOFA & $5(2,6)$ & $4(2,5)$ \\
\hline Sepsis* & $43(90 \%)$ & $43(90 \%)$ \\
\hline Septic shock* & $11(23 \%)$ & $6(13 \%)$ \\
\hline Normal to increased $\mathrm{LVEF}^{\dagger}$ & $44(92 \%)$ & $41(85 \%)$ \\
\hline Lactate (mmol/L) & $4.9(3.2)$ & $4.4(2.4)$ \\
\hline Baseline NT-proBNP $(\mathrm{pg} / \mathrm{ml})^{\ddagger}$ & $\begin{array}{l}950.7(435.5 \\
1946)\end{array}$ & $\begin{array}{l}1188.5(366 \\
2495.5)\end{array}$ \\
\hline $\mathrm{P} / \mathrm{F}$ ratio at baseline $(\mathrm{mmHg})$ & $364.9(174.0)$ & $328.7(134.3)$ \\
\hline \multicolumn{3}{|c|}{ Intravenous fluid before randomization (ml) } \\
\hline None & $40(83 \%)$ & $39(79 \%)$ \\
\hline 200 & $5(10 \%)$ & $5(10 \%)$ \\
\hline $201-500$ & $3(6 \%)$ & $5(10 \%)$ \\
\hline \multicolumn{3}{|l|}{ Site of infection } \\
\hline Respiratory tract & $23(48 \%)$ & $19(40 \%)$ \\
\hline Urinary tract & $10(21 \%)$ & $10(21 \%)$ \\
\hline Intraabdominal & $10(21 \%)$ & $10(21 \%)$ \\
\hline Bloodstream & $2(4 \%)$ & $1(2 \%)$ \\
\hline Central nervous system & 0 & $1(2 \%)$ \\
\hline Other/unknown & $3(6 \%)$ & $7(15 \%)$ \\
\hline
\end{tabular}

Table 1 Baseline Characteristics of the participants (Continued)

\begin{tabular}{lll}
\hline & $\begin{array}{l}\text { Standard rate } \\
(\boldsymbol{n}=\mathbf{4 8})\end{array}$ & $\begin{array}{l}\text { Limited rate } \\
(\boldsymbol{n}=\mathbf{4 8})\end{array}$ \\
\hline Baseline syndecan-1 level $(\mathrm{ng} / \mathrm{ml})^{\S}$ & \\
Median (Q1, Q3) & $205(136,378)$ & $222(126,759)$ \\
Geometric mean (95\% Cl) & $258(179-373)$ & $312(217-451)$ \\
\hline
\end{tabular}

Data indicate the mean (SD), median (Q1, Q3), or $n(\%)$ unless otherwise stated

APACHE Acute Physiology and Chronic Health Evaluation, SOFA Sequential Organ Failure Assessment, LVEF left ventricular ejection fraction

${ }^{*}$ According to the sepsis-3 definition [16].

${ }^{\dagger}$ According to the qualitative LVEF estimations [17].

${ }^{\text {F}}$ Six data points are missing in the standard-rate group and four are missing in the limited-rate group due to administrative reasons

${ }^{5}$ One data point is missing in the limited infusion rate group due to

administrative reasons

primary outcome in the standard and limited infusion rate groups, respectively. Forty-eight patients per group were analyzed regarding all other analyses not related to the syndecan-1 test. The patient flow diagram is shown in Fig. 1. The baseline characteristics of patients in both groups are comparable, but patients in the limited-rate group exhibited greater hemodynamic stability in general and had a higher prevalence of previous systemic steroid use (Table 1).

\section{Treatments during the 6-h intervention period}

During the intervention period, the fluid administered in the limited-rate group was less than that of the standard-rate group ( $39 \mathrm{ml} / \mathrm{kg}$ IQR $35-52 \mathrm{ml} / \mathrm{kg}$ vs. 53 $\mathrm{ml} / \mathrm{kg}$ IQR $46-64 \mathrm{ml} / \mathrm{kg} ; p<0.001)$. Patients in the limited-rate group were less likely to received vasopressors $(17 \%$ vs. $42 \% ; p=0.007)$ compared to the standardrate group. There was no difference in vasopressor dose between the groups. The use of mechanical ventilation was less frequent in the limited-rate group than in the standard-rate group (23\% vs. $42 \%: p=0.049)$. The use of corticosteroids was comparable in both groups $(8 \%$ vs. $10 \% p=0.73$ ), and there was no difference in the use of albumin or time to antibiotics (Table 2). The hemodynamic data of the patients during the intervention were showed in Supplementary Table S1. The hourly fluid administration, vasopressor, and mechanical ventilation were depicted in Supplementary Figure S1, S2, and 3, respectively.

\section{Primary outcome}

The geometric means of syndecan-1 in the standard-rate $(n=46)$ and limited-rate $(n=44)$ groups were $265 \mathrm{ng} /$ $\mathrm{ml}(95 \% \mathrm{CI} 182-388 \mathrm{ng} / \mathrm{ml})$ and 301 (95\% CI 206-442 $\mathrm{ng} / \mathrm{ml})$ at baseline and $293 \mathrm{ng} / \mathrm{ml}$ (95\% CI 209-410 $\mathrm{ng} /$ $\mathrm{ml})$ and $273(95 \% \mathrm{CI} 183-408 \mathrm{ng} / \mathrm{ml})$ at $6 \mathrm{~h}$, respectively. There was no significant difference in changes of syndecan-1 level at $6 \mathrm{~h}$ (GMR in the limited-rate group, 0.82; 95\% CI 0.66-1.02; $p=0.07$ ) (Fig. 2). When the data 
Table 2 Treatments during the 6-h intervention period

\begin{tabular}{llll}
\hline & Standard rate $(\boldsymbol{n}=\mathbf{4 8})$ & Limited rate $(\boldsymbol{n}=\mathbf{4 8})$ & $\boldsymbol{p}$ value \\
\hline Vasopressor use & $20(42 \%)$ & $8(17 \%)$ & 0.007 \\
Mechanical ventilation & $20(42 \%)$ & $11(23 \%)$ & 0.049 \\
-Started after enrollment & $16(33 \%)$ & $9(19 \%)$ & 0.10 \\
Steroid use & $5(10 \%)$ & $4(8 \%)$ & 0.73 \\
Albumin use & $2(4 \%)$ & $2(4 \%)$ & $>0.99$ \\
Time to antibiotics from triage $(\mathrm{min})$ & $42(30.5,57.5)$ & $49(39,66)$ & 0.06 \\
\hline
\end{tabular}

Data are $n(\%)$ and median (Q1, Q3)

were adjusted for differences in baseline and treatment (hemodynamic status and vasopressor use within 6-h period), the difference remained insignificant (GMR in the limited-rate group, 0.80 ; 95\% CI 0.64-1.00; $p=0.05$ ). According to the per-protocol analysis (42 patients in the standard-rate and 38 patients in the limited-rate group), there was no difference between the groups (GMR in the limited-rate group, 0.84 95\% CI (0.66-1.06; $p=0.07)$.

\section{Changes of syndecan-1 level within groups}

The median syndecan-1 levels in the standard-rate group were $205 \mathrm{ng} / \mathrm{ml}$ (IQR 136-378 ng/ml) and $220 \mathrm{ng} / \mathrm{ml}$ (IQR $157-519 \mathrm{ng} / \mathrm{ml}$ ) at baseline and $6 \mathrm{~h}$, respectively. The median syndecan-1 levels in the limited-rate group were $221 \mathrm{ng} / \mathrm{ml}$ (IQR 127-759 ng/ml) and $198 \mathrm{ng} / \mathrm{ml}$ (IQR $106-487 \mathrm{ng} / \mathrm{ml}$ ) at baseline and $6 \mathrm{~h}$, respectively. During the 6-h intervention period, there was no significant different change of syndecan-1 level within the standard-rate and limited rate groups $(p=0.23$ and 0.77 , respectively).

\section{Protocol adherence}

Protocol adherence was high in both groups since termination of the protocol occurred in only six patients (12\%) in the limited-rate group and in five patients $(10 \%)$ in the standard-rate group. The reasons for

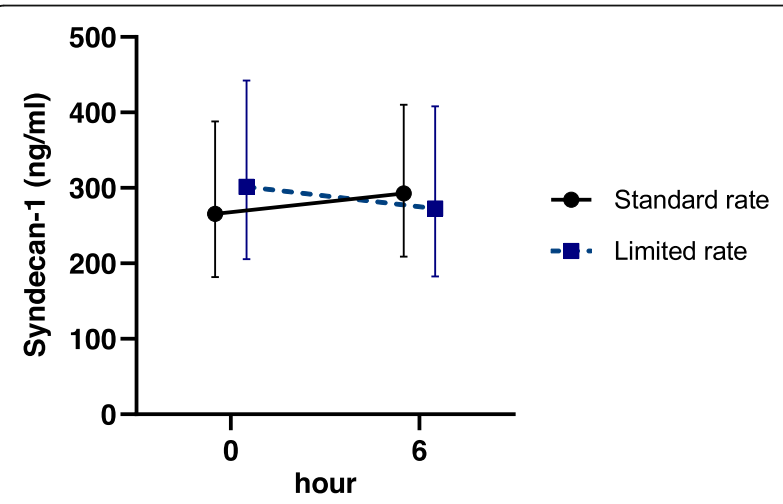

Fig. 2 Changes in syndecan-1 levels from baseline to 6 h. (Data are presented as the geometric mean and error bars represent 95\% confidence interval) protocol termination were the physicians' decision to change the type of intravenous fluid, the patients exhibited signs of fluid overload, and physicians' decision to increase the rate of intravenous fluid (Fig. 1).

\section{Adverse events during intervention}

There was one adverse event of cardiogenic pulmonary edema in the standard-rate group and two in the limited-rate group. There were no new arrhythmias or extravasation of peripherally administered vasopressors in either group. In the standard-rate group, one participant died during the intervention period due to lifethreatening massive hemoptysis. This fatal event was reviewed and reported to the ethics committee and was considered unrelated to the intervention.

\section{Secondary outcomes}

Regarding physiological parameters, there were no significantly different changes in 6-h lactate clearance, the proportion of patients with MAP $\geq 65 \mathrm{mmHg}$ at $1 \mathrm{~h}$ and $6 \mathrm{~h}$, or the P/F ratio at $6 \mathrm{~h}$. Fluid input per body weight at $24 \mathrm{~h}$ was lower in the limited-rate group, but at $72 \mathrm{~h}$, the volume of fluid used was comparable in both groups. There was no difference between the groups with respect to fluid balance at 24 or $72 \mathrm{~h}$, organ failure-free days or hospital length of stay. The 90-day mortality was $18.8 \%$ and $31.3 \%$ in the limited-rate group and standardrate group, respectively (relative risk in the limited-rate group 0.60 (95\% CI $0.29-1.24 ; p=0.16$ ). The data are summarized in Table 3.

\section{Subgroup analysis}

No significant difference was observed regarding the effect of limited rate according to the pre-specified subgroups, baseline syndecan-1 levels, NT-proBNP, lactate, or APACHE II score ( $p=0.14$ to 0.50 for interaction) (Fig. 3).

\section{Discussion}

In this randomized controlled trial examining resuscitating patients with sepsis-induced hypoperfusion in the $\mathrm{ED}$, the limited rate of fluid resuscitation compared to the standard rate did not significantly reduce changes in 
Table 3 Secondary outcomes

\begin{tabular}{|c|c|c|c|c|}
\hline & Standard rate $(n=48)$ & Limited rate $(n=48)$ & $\begin{array}{l}\text { Point estimates }(95 \% \\
\text { Cl)* }\end{array}$ & $\begin{array}{l}p \\
\text { value }\end{array}$ \\
\hline 6-h lactate clearance (\%) & $(n=46) 26.8(39.8)$ & $(n=46) 26.4(38.1)$ & $\begin{array}{l}\text { Mean difference }-0.5 \% \\
(-16 \text { to } 15.6 \%)\end{array}$ & 0.95 \\
\hline Patients with MAP $\geq 65 \mathrm{mmHg}$ at $1 \mathrm{~h}$ & $36 / 47(77 \%)$ & $42 / 47(89 \%)$ & RR 1.17(0.97-1.41) & 0.049 \\
\hline Patients with MAP $\geq 65 \mathrm{mmHg}$ at $6 \mathrm{~h}$ & $43 / 47(92 \%)$ & $43 / 48(90 \%)$ & RR 0.98(0.86-1.12) & 0.73 \\
\hline $\mathrm{P} / \mathrm{F}$ ratio at $6 \mathrm{~h}(\mathrm{mmHg})$ & $(n=46) 337(178)$ & $(n=46) 363(159)$ & $\begin{array}{l}\text { Mean difference } 26 \\
(-44 \text { to } 96)\end{array}$ & $>0.99$ \\
\hline Fluid input in $6 \mathrm{~h}(\mathrm{ml})$ & $\begin{array}{l}(n=47) 2600(2100 \\
3489)\end{array}$ & $\begin{array}{l}(n=48) 2238(1898 \\
2488)\end{array}$ & & 0.003 \\
\hline Fluid input per body weight in $6 \mathrm{~h}(\mathrm{ml} / \mathrm{kg})$ & $(n=47) 53(46,64)$ & $(n=48) 39(35,52)$ & & $<0.001$ \\
\hline Fluid input per body weight in $24 \mathrm{~h}(\mathrm{ml} / \mathrm{kg})$ & $(n=40) 115(86,146)$ & $(n=45) 88(63,111)$ & & 0.02 \\
\hline Fluid balance in $24 \mathrm{~h}(\mathrm{ml})$ & $\begin{array}{l}(n=40) 3758(1237 \\
4975)\end{array}$ & $\begin{array}{l}(n=43) 2896(1520 \\
4535)\end{array}$ & & 0.68 \\
\hline Fluid input per body weight in $72 \mathrm{~h}(\mathrm{ml} / \mathrm{kg})$ & $(n=37) 175(124,220)$ & $(n=37) 150(108,229)$ & & 0.70 \\
\hline Fluid balance in $72 \mathrm{~h}(\mathrm{ml})$ & $\begin{array}{l}(n=37) 3140(377 \\
5524)\end{array}$ & $\begin{array}{l}(n=36) 4100(2636 \\
7090)\end{array}$ & & 0.13 \\
\hline Requirement for vasopressors & $27 / 42(64 \%)$ & $20 / 46(43 \%)$ & RR $0.68(0.45-1.01)$ & 0.05 \\
\hline Days alive and free from vasopressors up to 28 days & $(n=44) 26(0,28)$ & $(n=46) 27.5(22,28)$ & & 0.13 \\
\hline Requirement for mechanical ventilation & $21 / 42(50 \%)$ & 19/46 (41\%) & RR $0.83(0.52-1.31)$ & 0.41 \\
\hline $\begin{array}{l}\text { Days alive and free from mechanical ventilation up to } 28 \\
\text { days }\end{array}$ & $(n=44) 27.5(0,28)$ & $(n=46) 27(9,28)$ & & 0.91 \\
\hline Requirement for new RRT & $4 / 42(10 \%)$ & $6 / 46(13 \%)$ & RR $1.34(0.41-4.52)$ & 0.74 \\
\hline Days alive and free from RRT up to 28 days & $(n=44) 28(0,28)$ & $(n=46) 28(21,28)$ & & 0.60 \\
\hline Days alive and free from organ failure up to 28 days & $(n=44) 25(0,27.5)$ & $(n=46) 26(9,28)$ & & 0.37 \\
\hline Hospital LOS (day) & $6(5,14)$ & $11(3.5,25)$ & & 0.23 \\
\hline 28-day mortality & $12 / 48(25 \%)$ & $8 / 48(17 \%)$ & RR 0.67 (0.30-1.48) & 0.32 \\
\hline 90-day mortality & 15/48 (31\%) & 9/48 (19\%) & RR 0.60 (0.29-1.24) & 0.16 \\
\hline
\end{tabular}

Data are mean (SD), $n /$ total $n(\%)$ and median $(\mathrm{Q} 1, \mathrm{Q} 3)$

MAP mean arterial pressure, $P / F \mathrm{PaO}_{2} / \mathrm{FiO}_{2}, R R$ relative risk, $R R T$ renal replacement therapy, LOS length-of-stay

*Point estimates are for the limited-rate group compared to the standard-rate group

syndecan-1 at 6 h. However, reduced 6-h and 24-h fluid input volumes were observed in the limited-rate group compared to the standard-rate strategy. There was no significant difference in organ failure outcomes, adverse events, or mortality rate between the two groups.

Previous studies have reported an association between hypervolemia from rapid fluid administration and glycocalyx shedding as measured by syndecan-1 $[13,14,20]$. In an animal model of sepsis, rapid fluid administration $(30 \mathrm{ml} / \mathrm{kg} / \mathrm{h}$ ) resulted in increased syndecan-1 shedding compared to the slower rate $(10 \mathrm{ml} / \mathrm{kg} / \mathrm{h})$ [20]. In humans, increased syndecan- 1 levels were detected after rapid fluid bolus in $15 \mathrm{~min}$ [13]. Higher levels of syndecan-1 were observed after fluid bolus in healthy preoperative patients, concurrently with higher levels of atrial natriuretic peptide (ANP) [14]. Released in response to hypervolemia, the peptide hormone ANP, and brain natriuretic peptide (BNP) were found to have in vivo activity with respect to glycocalyx shedding [21]. Moreover, rapid fluid bolus administration could lead to shear stress that directly activates secretion of matrix metalloproteinases from endothelial cells and stimulates glycocalyx shedding [22]. Though a limited-rate strategy may mitigate transient hypervolemia and shear stress from fluid administration, our study did not show a significant reduction of changes in syndecan-1 between different fluid resuscitation strategies. This finding could be explained by heterogeneity of the septic patients, which resulted in differences in patient characteristics in this small, randomized controlled trial since destruction of the endothelial glycocalyx can result from various factors, such as the inflammation, hypoxia, or vasopressor administration [19, 23, 24]. In our study, after adjusting for differences in hemodynamic instability and vasopressor administration, the effect of the limited-rate fluid strategy on pre- and post-treatment reduction in syndecan-1 levels was more pronounced but still insignificant.

Interestingly, in the standard-rate group, the use of vasopressors was more frequent than in the limited-rate 


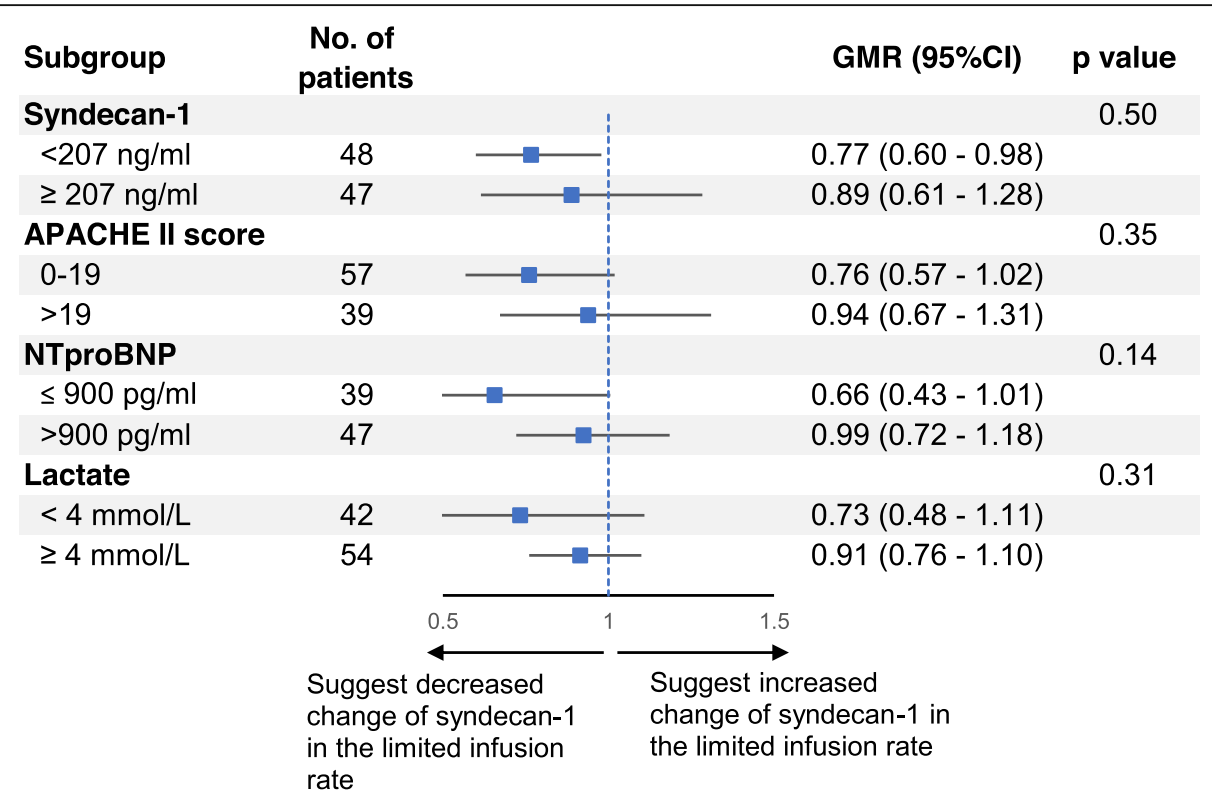

Fig. 3 Prespecified subgroup analysis. $p$ value for the interaction. (GMR: geometric mean ratio; Cl: confidence interval; APACHE: Acute Physiology and Chronic Health Evaluation; NT-proBNP: N-terminal pro-b-type natriuretic peptide)

group. This could partially be explained by imbalanced baseline characteristics of the participants: there were more patients with hemodynamic instability in the standard-rate group. Moreover, the proportion of mechanically ventilated patients at enrollment in the standard-rate group was higher than that in the limitedrate group (Supplementary Figure S3). This might also explain the increased use of vasopressors in the standard-rate group since mechanical ventilation potentially induced hemodynamic instability in preloaddependent patients [25]. However, previous studies also potentially provide a partial explanation from evidence of the inefficacy of rapid fluid bolus administration. In a volume kinetics study in human volunteers, the fraction of infused crystalloid that remained in the plasma was higher in response to a lower rate of infusion [26]. Another study found that cardiac output increased by $0.02 \mathrm{~L} / \mathrm{min}$ in the slower fluid bolus (rate $500 \mathrm{ml} / \mathrm{h}$ ) compared to the rapid fluid bolus (rate $2000 \mathrm{ml} / \mathrm{h}$ ). The effect returned to baseline after infusion was complete [27].

Our study demonstrated that the limited-rate strategy led to a reduction in fluid volume used at 6 and $24 \mathrm{~h}$ without significant adverse events or any difference in clinical outcomes. However, this study was not adequately powered to detect differences and thus should be considered exploratory. A significant difference in clinical outcomes was not demonstrated in previous pilot studies of limited volume fluid resuscitation. In a pilot randomized study in an intensive care setting, patients with septic shock treated with the restrictive fluid approach received less fluid during the initial 5 days than those with treated with the liberal strategy (absolute difference $-1.2 \mathrm{~L} ; 95 \% \mathrm{CI}-2.0$ to $-0.4 \mathrm{~L}$ ), and there was a signal towards mitigating kidney injury in restrictive fluid approach [28]. In the ED setting, implementation of the limited volume of resuscitation coupled with early vasopressor use was feasible and was associated with a decreased amount of fluid during the initial phase of resuscitation [29]. A large study that comparing the clinical outcomes of various fluid resuscitation approaches is currently being conducted and is potentially powered to determine their effects on relevant outcomes [30].

To our knowledge, this study is the first randomized trial comparing different fluid rate strategies during the very early phase of resuscitation in septic patients in the emergency department. The type of resuscitation fluid was controlled provided that different fluid types were associated with different magnitude of glycocalyx damage [31]. However, there are several notable limitations. First, the investigators, healthcare providers, and patients were not blinded to the study procedures; therefore, potential biases may affect recognition and treatment in open-label trials. However, we measured objective outcomes that are less susceptible to misclassification. Second, despite the appropriate randomization method, participants between the groups exhibited distinct different baseline characteristics. An adjusted analysis was performed to mitigate this disparity. Third, assessment of glycocalyx integrity with direct visualization (e.g., intravital microscopy) or using mass spectrometry 
potentially yields more accurate results than does the detection of plasma syndecan-1 by ELISA methods. However, measuring syndecan-1 levels is much more clinically practical. Syndecan-1 is negatively correlated with changes in glycocalyx thickness and positively correlated with changes in microvascular permeability [32]. Furthermore, syndecan-1 was extensively studied regarding correlations with clinical outcome [11]. Higher levels of syndecan- 1 are associated with organ failure and mortality in septic patients [33, 34]. Since the dispersion of syndecan-1 levels are too large compared to effect size, larger studies with more participants are needed to potentially detect the differences in the magnitude of glycocalyx shedding and to highlight the effects of different fluid strategies on important clinical outcomes. Lastly, the infusion rate of fluid administration is definitely associated with its total volume. In our study, patients in the limited-rate group received lower fluid volume than that of the other. Although we aimed to investigate the effect of rate on the marker of glycocalyx shedding, the outcomes could have been affected by the difference in fluid volume.

\section{Conclusions}

In patients with sepsis-induced hypoperfusion, the administration of resuscitative fluid with a limited fluid infusion rate did not significantly reduce changes in syndecan- 1 at $6 \mathrm{~h}$, but it reduced the volume used during the early resuscitation compared to patients resuscitated using the standard-rate approach.

\section{Supplementary Information}

The online version contains supplementary material available at https://doi. org/10.1186/s40560-020-00515-7.

Additional file 1: Table S1. Hemodynamic data of the patients during the intervention. Figure S1. Mean hourly intravenous fluid volume per body weight $(\mathrm{ml} / \mathrm{kg})$ during the 6 -hour intervention period. The error bars represent the standard deviation. Figure S2. Cumulative number of patients with the need of vasopressors during the 6-hour intervention period. Figure S3. Cumulative number of mechanically-ventilated patients during the 6-hour intervention period.

\section{Abbreviations}

ANP: Atrial natriuretic peptide; APACHE: Acute Physiology and Chronic Health Evaluation; BMI: Body mass index; BNP: Brain natriuretic peptide; Cl: Confidence interval; CONSORT: Consolidated Standards of Reporting Trials; DNAR: Do-not-attempt-resuscitation; ED: Emergency department; EDTA: Ethylenediaminetetraacetic acid; ELISA: Enzyme-linked immunosorbent assay; ESRD: End-stage renal disease; GMR: Geometric mean ratio; IQR: Interquartile range; IRB: Institutional Review Board; LOS: length-of-stay; LRS: Lactated Ringer's solution; LVEF: Left ventricular ejection fraction; MAP: Mean arterial pressure; NT-proBNP: N-terminal pro-b-type natriuretic peptide; P/F: PaO2/FiO2; POCUS: Point-of-care ultrasound; qSOFA: Quick sequential organ failure assessment; RRT: Renal replacement therapy; SBP: Systolic blood pressure; SD: Standard deviation; SSC: Surviving Sepsis Campaign; TCTR: Thai Clinical Trials Registry

\section{Acknowledgements}

We would like to thank Kanchana Prasith for general management. We would like to thank our emergency medicine and internal medicine colleagues for supporting our study.

\section{Authors' contributions}

IS designed the study, recorded and analyzed the data, interpreted the findings, prepared the figures, and drafted the manuscript. LW recorded the data and revised the manuscript. NS contributed to the design of the study and revised the manuscript. KM supervised the study, interpreted the findings and revised the manuscript. All authors read and approved the final manuscript.

\section{Funding}

This work was supported by the Ratchadapiseksompotch Fund, Faculty of Medicine, Chulalongkorn University (grant number RA62/039); the Ratchadaphiseksomphot Endowment Fund, Faculty of Medicine,

Chulalongkorn University (grant number RA-MF-3/63); The 100th Anniversary Chulalongkorn University Fund for Doctoral Scholarship; and The 90th Anniversary Chulalongkorn University Fund (Ratchadaphiseksomphot Endowment Fund). The funders had no role in designing or analyzing the results.

\section{Availability of data and materials}

The datasets used and/or analyzed during the current study are available from the corresponding author on reasonable request.

\section{Ethics approval and consent to participate}

The study was conducted in accordance with the international guidelines for human research protection as Declaration of Helsinki, The Belmont Report, CIOMS Guideline and International Conference on Harmonization in Good Clinical Practice (ICH-GCP) and was approved by the Institutional Review Board of the Faculty of Medicine, Chulalongkorn University, Bangkok, Thailand (IRB No. 431/61). Patients were enrolled after written informed consent was obtained from the patients or their legal representatives.

\section{Consent for publication}

Not applicable

\section{Competing interests}

The authors declare that they have no competing interests.

\section{Author details}

'Division of Academic Affairs, Faculty of Medicine, Chulalongkorn University, Bangkok, Thailand. ${ }^{2}$ Department of Emergency Medicine, King Chulalongkorn Memorial Hospital, The Thai Red Cross Society, 1873 Rama IV Road, Pathumwan, Bangkok 10330, Thailand. ${ }^{3}$ Division of Nephrology, Department of Medicine, and Critical Care Nephrology Research Unit, Faculty of Medicine, Chulalongkorn University, Bangkok, Thailand. ${ }^{4}$ Excellent Center for Critical Care Nephrology, King Chulalongkorn Memorial Hospital, Bangkok, Thailand.

${ }^{5}$ Academy of Science, Royal Society of Thailand, Bangkok, Thailand.

${ }^{6}$ Department of Medicine, Faculty of Medicine, Chulalongkorn University, Bangkok, Thailand.

Received: 10 November 2020 Accepted: 14 December 2020

Published online: 05 January 2021

\section{References}

1. Levy MM, Evans LE, Rhodes A. The surviving sepsis campaign bundle: 2018 update. Intensive Care Med. 2018;44(6):925-8.

2. Hoste EA, Maitland K, Brudney CS, Mehta R, Vincent JL, Yates D, et al. Four phases of intravenous fluid therapy: a conceptual model. Br J Anaesth. 2014; 113(5):740-7.

3. Hu B, Chen JCY, Dong Y, Frank RD, Passe M, Portner E, et al. Effect of initial infusion rates of fluid resuscitation on outcomes in patients with septic shock: a historical cohort study. Crit Care. 2020;24(1):137.

4. Nunes TS, Ladeira RT, Bafi AT, de Azevedo LC, Machado FR, Freitas FG. Duration of hemodynamic effects of crystalloids in patients with circulatory shock after initial resuscitation. Ann Intensive Care. 2014;4:25.

5. Bihari S, Teubner DJ, Prakash S, Beatty T, Morphett M, Bellomo R, et al. Fluid bolus therapy in emergency department patients: indications and physiological changes. Emerg Med Australas. 2016;28(5):531-7. 
6. Lipcsey M, Chiong J, Subiakto I, Kaufman MA, Schneider AG, Bellomo R. Primary fluid bolus therapy for infection-associated hypotension in the emergency department. Crit Care Resusc. 2015;17(1):6-11.

7. Seymour CW, Gesten F, Prescott HC, Friedrich ME, Iwashyna TJ, Phillips GS, et al. Time to treatment and mortality during mandated emergency care for sepsis. N Engl J Med. 2017:376(23):2235-44.

8. Sankar J, Ismail J, Sankar MJ. C PS, Meena RS. Fluid Bolus Over 15-20 Versus 5-10 minutes each in the first hour of resuscitation in children with septic shock: a randomized controlled trial. Pediatr Crit Care Med. 2017;18(10): e435-e45

9. Maitland K, Kiguli S, Opoka RO, Engoru C, Olupot-Olupot P, Akech SO, et al. Mortality after fluid bolus in African children with severe infection. N Engl J Med. 2011;364(26):2483-95.

10. Andrews B, Semler MW, Muchemwa L, Kelly P, Lakhi S, Heimburger DC, et al. Effect of an early resuscitation protocol on in-hospital mortality among adults with sepsis and hypotension: a randomized clinical trial. Jama. 2017;318(13):1233-40.

11. Uchimido R, Schmidt EP, Shapiro NI. The glycocalyx: a novel diagnostic and therapeutic target in sepsis. Crit Care. 2019;23(1):16.

12. Berg S, Engman A, Hesselvik JF, Laurent TC. Crystalloid infusion increases plasma hyaluronan. Crit Care Med. 1994;22(10):1563-7.

13. Powell MF, Mathru M, Brandon A, Patel R, Frölich MA. Assessment of endothelial glycocalyx disruption in term parturients receiving a fluid bolus before spinal anesthesia: a prospective observational study. Int J Obstet Anesth. 2014;23(4):330-4.

14. Chappell D, Bruegger D, Potzel J, Jacob M, Brettner F, Vogeser M, et al. Hypervolemia increases release of atrial natriuretic peptide and shedding of the endothelial glycocalyx. Crit Care. 2014;18(5):538.

15. Hippensteel JA, Uchimido R, Tyler PD, Burke RC, Han X, Zhang F, et al. Intravenous fluid resuscitation is associated with septic endothelial glycocalyx degradation. Crit Care. 2019;23(1):259.

16. Singer M, Deutschman CS, Seymour CW, Shankar-Hari M, Annane D, Bauer $M$, et al. The third international consensus definitions for sepsis and septic shock (Sepsis-3). JAMA. 2016;315(8):801-10.

17. Weekes AJ, Tassone HM, Babcock A, Quirke DP, Norton HJ, Jayarama K, et al. Comparison of serial qualitative and quantitative assessments of caval index and left ventricular systolic function during early fluid resuscitation of hypotensive emergency department patients. Acad Emerg Med. 2011;18(9): 912-21.

18. Harris PA, Taylor R, Thielke R, Payne J, Gonzalez N, Conde JG. Research electronic data capture (REDCap)--a metadata-driven methodology and workflow process for providing translational research informatics support. J Biomed Inform. 2009:42(2):377-81.

19. Steppan J, Hofer S, Funke B, Brenner T, Henrich M, Martin E, et al. Sepsis and major abdominal surgery lead to flaking of the endothelial glycocalix. J Surg Res. 2011;165(1):136-41.

20. Wu X, Hu Z, Yin Y, Li Y, Zhu G, Yu B. Changes of endothelial glycocalyx and effect of fluid resuscitation combined with norepinephrine on endothelial glycocalyx in early septic shock. Int J Clin Exp Med. 2018;11(2):1343-51.

21. Jacob M, Saller T, Chappell D, Rehm M, Welsch U, Becker BF. Physiological levels of A-, B- and C-type natriuretic peptide shed the endothelial glycocalyx and enhance vascular permeability. Basic Res Cardiol. 2013;108(3):347.

22. Kang H, Duran CL, Abbey CA, Kaunas RR, Bayless KJ. Fluid shear stress promotes proprotein convertase-dependent activation of MT1-MMP. Biochem Biophys Res Commun. 2015;460(3):596-602.

23. Ward BJ, Donnelly JL. Hypoxia induced disruption of the cardiac endothelial glycocalyx: implications for capillary permeability. Cardiovasc Res. 1993:27(3):384-9.

24. Martin JV, Liberati DM, Diebel LN. Disparate effects of catecholamines under stress conditions on endothelial glycocalyx injury: an in vitro model. Am J Surg. 2017;214(6):1166-72

25. Duke GJ. Cardiovascular effects of mechanical ventilation. Crit Care Resusc. 1999;1(4):388-99.

26. Hahn RG, Drobin D, Ståhle L. Volume kinetics of Ringer's solution in female volunteers. Br J Anaesth. 1997;78(2):144-8.

27. Ukor IF, Hilton AK, Bailey MJ, Bellomo R. The haemodynamic effects of bolus versus slower infusion of intravenous crystalloid in healthy volunteers. J Crit Care. 2017;41:254-9.

28. Hjortrup PB, Haase N, Bundgaard $H$, Thomsen SL, Winding R, Pettilä V, et al. Restricting volumes of resuscitation fluid in adults with septic shock after initial management: the CLASSIC randomised, parallel-group, multicentre feasibility trial. Intensive Care Med. 2016:42(11):1695-705.

29. Macdonald SPJ, Keijzers G, Taylor DM, Kinnear F, Arendts G, Fatovich DM, et al. Restricted fluid resuscitation in suspected sepsis associated hypotension (REFRESH): a pilot randomised controlled trial. Intensive Care Med. 2018;44(12):2070-8.

30. Zampieri FG, Azevedo LCP, Corrêa TD, Falavigna M, Machado FR, Assunção MSC, et al. Study protocol for the Balanced Solution versus Saline in Intensive Care Study (BaSICS): a factorial randomised trial. Crit Care ResusC 2017;19(2):175-82

31. Torres Filho IP, Torres LN, Salgado C, Dubick MA. Plasma syndecan-1 and heparan sulfate correlate with microvascular glycocalyx degradation in hemorrhaged rats after different resuscitation fluids. Am J Physiol Heart Circ Physiol. 2016;310(11):H1468-78.

32. Torres LN, Chung KK, Salgado CL, Dubick MA, Torres Filho IP. Low-volume resuscitation with normal saline is associated with microvascular endothelial dysfunction after hemorrhage in rats, compared to colloids and balanced crystalloids. Crit Care. 2017;21(1):160.

33. Smart L, Macdonald SPJ, Burrows S, Bosio E, Arendts G, Fatovich DM. Endothelial glycocalyx biomarkers increase in patients with infection during emergency department treatment. J Crit Care. 2017;42:304-9.

34. Anand D, Ray S, Srivastava LM, Bhargava S. Evolution of serum hyaluronan and syndecan levels in prognosis of sepsis patients. Clin Biochem. 2016; 49(10-11):768-76.

\section{Publisher's Note}

Springer Nature remains neutral with regard to jurisdictional claims in published maps and institutional affiliations.
Ready to submit your research? Choose BMC and benefit from:

- fast, convenient online submission

- thorough peer review by experienced researchers in your field

- rapid publication on acceptance

- support for research data, including large and complex data types

- gold Open Access which fosters wider collaboration and increased citations

- maximum visibility for your research: over $100 \mathrm{M}$ website views per year

At BMC, research is always in progress.

Learn more biomedcentral.com/submissions 